\title{
ТОМ \\ Engagement styles in an environmental citizen science project
}

\section{Yaela Naomi Golumbic, Ayelet Baram-Tsabari and Barak Fishbain}

Abstract

Keywords

DOI

Introduction
This paper identifies the diverse ways in which participants engage with science, through the same citizen science project. Using multiple data sources, we describe various activities conducted by citizen scientists in an air quality project, and characterize the motivations driving their engagement. Findings reveal several themes, indicative of participants motivations and engagement; worried residents, education and outreach, environmental action, personal interest and opportunistic engagement. The study further illustrates the interconnectivity between science communication and citizen science practices and calls for nurturing this relationship for the mutual advancement of both fields.

Citizen science; Public engagement with science and technology

https://doi.org/10.22323/2.19060203

Submitted: 22nd July 2020

Accepted: 9th September 2020

Published: 4th November 2020

Public engagement with science has evolved extensively over the past two decades since the introduction of the Web 2.0, social media and smart phone ownership. These have created both numerous communication challenges prompted by the glut of available information, and new opportunities for active engagement, accessibility and the transparency of scientific data. One of the fastest growing areas of public engagement with science that has been prompted by advances in technology, is the field of citizen science which provides opportunities for the public to engage in active scientific endeavors in collaboration with professional scientists [Bonney, Ballard et al., 2009; Bonney, Shirk et al., 2014]. By collecting scientific data, monitoring the environment, classifying images and sounds, asking scientific questions and analyzing data, citizens today can contribute to the co-creation of scientific knowledge. This provides new opportunities for science and society alike by challenging norms and reinforcing a more democratic approach to scientific investigation, evaluation and knowledge production [Storksdieck et al., 2016].

Citizen science calls for inclusiveness, reciprocity between project stakeholders [Golumbic, Orr et al., 2017; Soleri et al., 2016; Storksdieck et al., 2016] and the 
fostering of a two-way dialogue between citizens and scientists [Bonney, Phillips et al., 2016]. This echoes the Public Engagement with Science (PES) model, which advocates democratic processes such as increased transparency and collective decision making within science [Brossard and Lewenstein, 2009], and suggests that mutual benefits can be achieved by creating reciprocal relationships between scientists and other stakeholders of science [McCallie et al., 2009].

Participants in citizen science projects are often viewed as one collective group in the literature analyzing their motivations, derived benefits and outcomes. However, different audiences may have different motivations and needs when participating in citizen science projects [Cox et al., 2018; Tiago et al., 2017]. These may include addressing environmental hazards, as in the case of Global Community Monitor [Phillips et al., 2019], learning about the natural world as in the case of the Great Pollinator Project [Domroese and Johnson, 2017] and contributing to science, as in the case of SETI@home [Nov, Arazy and Anderson, 2011]. Considering each group's agenda and motivation for participating in citizen science is a key factor in encouraging greater participation and the retention of volunteers [Tiago et al., 2017]. While some projects direct themselves towards specific audiences and existing communities [e.g. Golumbic, Baram-Tsabari and Koichu, 2019], others provide opportunities for multiple audiences with diverse needs and levels of participation [e.g. Haklay, 2013].

Engagement in citizen science can take different forms, and ranges from passive to active [Eveleigh et al., 2014], from local to global [Roy et al., 2012], from virtual to location-based [Wiggins and Crowston, 2011] and a range of contribution and activity levels [Aristeidou, Scanlon and Sharples, 2017; Jackson et al., 2016]. Likewise, the activities available for participants to engage with are expanding as citizen science becomes more widespread. These include data collection, data classification and tagging, data analysis and interpretation, asking and answering research questions, community involvement and communication [Phillips et al., 2019; Wiggins and Crowston, 2015]. As projects develop and provide multiple opportunities for participants, the reasons why participants choose one activity over others may be of interest. Furthermore, as citizen science strives to involve diverse audiences and increase inclusiveness, it is important to investigate these audiences' characteristics.

In an attempt to better understand diverse audiences' potential interest and engagement with citizen science, we explored the underlying engagement styles of participants in an air quality citizen science project. Acknowledging there are many ways to be involved in citizen science, we examine the diversity in participants' interaction with the project and investigate the reasons which drive this engagement.

Science communication addresses the study of public processes of understanding and engaging with science [Bucchi and Trench, 2014]. Models of science communication have evolved over time, as discussed by Bauer [2009] and others, shifting from a deficit approach to a more deliberative approach, which considers science in the context of society. The Public Engagement with Science (PES) 
approach which has developed over the past 20 years, corresponds to the science communication "dialogue model", referring to mutualistic relationships between scientists and different publics. This model is based on the belief that scientists are not the sole experts, and scientific knowledge alone is not sufficient to fully address complex topics such as the development and application of science and technology in society [McCallie et al., 2009]. The PES model was extended by Trench [2008] who proposed dividing engagement into dialogue and participation. In his framework, dialogue is defined as communication between scientists and public representatives and is aimed at a specific applications or consultation. Participation is defined as communication with diverse groups based on the belief that all can contribute, and all have a stake in the outcome of the deliberations and discussions [Trench, 2008].

Citizen science has been defined by Bonney, Ballard et al. [2009] as Public Participation in Science Research (PPSR). A natural place for citizen science within the science communication models, would therefore appear to be within the participation model, which positions both scientists and publics as equal stakeholders who take part in shaping an issue, setting the agenda and negotiating meaning. However, citizen science projects are diverse and often vary in their level of inclusion [Bonney, Ballard et al., 2009; Haklay, 2013]. Thus different citizen science projects may align with different science communication models [Sagy et al., 2019]. For example, contributory projects that are initiated and managed by scientists and involve participants mainly in pre-defined data collection tasks (following a protocol designed by scientists) [Bonney, Ballard et al., 2009], may be considered low engagement levels. Such projects may better be aligned with the deficit model, which similarly utilizes a top to bottom approach as it addresses lay audiences [Brossard and Lewenstein, 2009]. In contrast, co-created projects that involve the public in all stages of the research process, including initiation and planning [Bonney, Ballard et al., 2009], correspond to a high engagement level and therefore could be aligned with the participation model, which considers all stakeholders as equally important.

Ultimately, citizen science varies in its level of participation between projects and thus cannot be collectively included in one science communication model. Schrögel and Kolleck [2019] suggested a three-dimensional framework describing the various modes of participation in science. The framework incorporates a normative focus (the degree to which the public is included in decision-making), an epistemic focus (the degree to which publics are included in knowledge generation processes) and a public outreach focus (the reach of a project beyond institutionalized scientists). Each of these dimensions describes a continuum between scientists and publics which jointly describe the many forms of public participation in science.

\section{Classification of citizen science participation and motivation}

Even within one project, participation levels may vary and participants may engage in different activities and express different behavioral traits [Haklay, 2013]. Such behavioral traits often relate to the level of activity in the project, from active members who contribute the majority of the work, through less active participants, and members who consume content, but do not contribute to community activities personally [Jackson et al., 2016]. Jackson et al. [2016] classified citizen science participants into three levels of contribution within one project: casual workers, 
community workers and focused workers. Similarly, Aristeidou, Scanlon and Sharples [2017] classified participants based on activity pattern profiles dubbed loyal, hardworking, persistent, lurker and visitor. These diverse definitions of participation demand a deeper investigation into participants' perspectives of citizen science and their underlying participatory choices. Such choices are largely influenced by motivational factors which relate closely to participants' emotional, behavioral, cognitive, and social experiences [Phillips et al., 2019].

The motivations for participating in citizen science may vary across projects and people. For example, Nov, Arazy and Anderson [2011], who investigated the online citizen science projects Stardust@home and SETI@home, found that participants' main motivation was their desire to contribute to scientific research. Rotman et al. [2012] found that participation in biodiversity citizen science projects was influences by participants' personal interest and pursuing an opportunity to extend and expand their scientific knowledge. This does not mean every project has a different set of motivations, rather that the balance in motivations may vary between projects, or between participants engaged in the same project [Cox et al., 2018; Tiago et al., 2017].

A systematic literature review of volunteers' motivations to participate in citizen science projects, conducted by Chako and Levontin [2019] revealed no less than 18 motivational categories identified in 42 research papers across citizen science projects from many disciplinary fields. These include self-direction - independent thought and action; stimulation - excitement, novelty, and change; nature universalism - preservation of the natural environment and many others. The many motivational categories and their multifaceted expressions underlie the complexity of motivational structures and their interconnectivity. They further highlight the role of motivation in shaping citizen science participation and engagement styles, in that individual-level motivations have been suggested to be powerful predictors of variations in citizen science volunteers' activities and retention [Cox et al., 2018]. This highlights the importance of understanding how and why people interact with citizen science projects, to best meet their needs and maintain their participation over time.

This study was conducted within the citizen science project "Sensing the Air" that monitors and facilitates air quality research in the local environment [Golumbic, Fishbain and Baram-Tsabari, 2019]. It was initiated in the city of Haifa, which is considered one of the most sensitive areas in Israel in terms of air pollution, due to the proximity of its industrial zone to residential areas [Israel Ministry of Environmental Protection, 2015]. Sensing the Air has two main activities: (A) monitoring air quality through the active involvement of volunteers and (B) facilitating the dissemination of air quality information to the public. As such it combines both citizen science and science communication practices, providing opportunities for large audiences to engage with air quality research and data.

Air quality monitoring implements static and mobile Micro Sensing Units (MSUs) which are deployed in several locations in collaboration with project participants. Locations include local schools, public spaces, private homes and other places of 
interest suggested by the participants. Measurements are transmitted automatically from the sensors to a central database, and serve two purposes: 1) they enable scientists to model air quality and examine the validity of the sensor network, and 2) they enable participants to conduct personal investigations of air quality in their local environment, identify air pollution hazards and reduce exposure. This air quality information can be accessed on the Sensing the Air platform, which presents both sensor data (collected through Sensing the Air sensors) and official data (collected by the government and municipalities), in a simple, user-friendly display designed for the use of non-experts and project participants [Golumbic, Fishbain and Baram-Tsabari, 2020; Golumbic, Fishbain and Baram-Tsabari, 2019]

Most participants in Sensing the Air are adult members of the public, who are non-experts in air quality but interested or concerned about the impact of air pollution. They were introduced to the project through social media, local media coverage, internet searches and word of mouth. Participants are divided to platform participants- those who view and interact with air quality information on the project platform, and sensor participants- those who host sensors in their home and/or perform personalized investigations and measurements in places of interest. In most cases, sensor participants were also platform participants, as the information from their investigations fed into the main project platform.

\section{Research design and sample}

In line with the two main activities of Sensing the Air (monitoring and presenting air quality data), and the two types of project participants (platform and sensor participants), this research was designed to investigate engagement styles of participants involved in each of these activities. We start the investigation using a broad perspective by accessing and analyzing the log data of the project platform, gradually focusing the study on personal views of participants using survey data and interviews. Using an inductive approach and integrating a variety of research tools, this study design allowed a sensitive, insightful and rich exploration of data, exposing structures and underlying patterns of engagement [Thomas, 2006].

The research population for this study were participants in Sensing the Air, as defined above, divided to platform participants and sensor participants.

Participants were invited to take part in this study through Sensing the Air website, e-mail listings, and project social media.

Our sample of platform participants included $n=436$ registered platform users and $n=123$ survey respondents. Survey respondents were $57 \%$ female with an average age of 40 and were mostly highly educated (i.e. holding tertiary qualifications).

Our sample of sensor participants includes $n=25$. Similar to survey respondents, sensor participants ranged in age from 20 to 70, with an average age of about 40, of whom 15 women and 10 men. Most sensor participants were highly educated, with $50 \%$ having a scientific or engineering degree and only $20 \%$ without academic qualifications. These demographics are consistent with other citizen science projects [as illustrated by Soleri et al., 2016, in a multiple, global project study], which tend to engage educated participants, however, it was more diverse in terms of age and gender. 


\section{Data collection and analysis}

Data collection combined multiple data sources and research tools, which were used to construct a comprehensive understanding of engagement styles, assist interpretation and preform triangulation to determine the consistency of the data [Patton, 1999]. These included semi structured interviews, questionnaires, participation reports, online comments and correspondence with participants and $\log$ data from the project website, as detailed below.

The data collection spanned three years from August 2015 to August 2018. All the data were collected and analyzed in Hebrew and representative segments were translated into English. An IRB approval was obtained from the Technion Institutional Ethics Committee (approval: Nov. 2014).

Log data from the project website. Data logging was automatically conducted by the website operating system throughout the duration of the study, recording all activities within the project platform. Log files included time and date of each site visit, login of users, and activities such as viewing data, creating graphs and reporting hazards. This data were used to discover usage behavior and browsing patterns as described by Grace, Maheswari and Nagamalai [2011]. Data were analyzed for each participant to determine the number and duration of visits and types of activities conducted during the visits.

Questionnaire. A questionnaire examining the extent to which participants understood the air quality data presented in the project platform and their perceptions as regards the project, was reported on previously [Golumbic, Fishbain and Baram-Tsabari, 2020]. Here, we reconceptualize the data and add interpretation based on previously unreported open-ended questions addressing participants perceptions of Sensing the Air.

The questionnaire was distributed to all Sensing the Air participants for a total of $\mathrm{n}=123$ respondents. Responses to open ended questions were received from about half of respondents, and were thematically analyzed to form codes of repeated ideas and recurring themes, and were each classified to one or more topics [Bazeley, 2013]. Intercoder reliability was examined and found to be above $90 \%$ agreement.

Semi structured interview. Interviews were conducted with sensor participants, before or during participation and focused on participants' perceptions, motivations and expectations from participating in Sensing the Air. The interviews were conducted individually, lasted about one hour and were conducted mainly in participants' homes or in the interviewer's office (according to participants' preference). Interviews were recorded, transcribed, and qualitatively analyzed using thematic analysis [Guest, MacQueen and Namey, 2012] and used to determine participants' views on air quality, reasons for participating and expectations from Sensing the Air.

Investigation report and feedback. Sensor participants who conducted personal investigations were asked to share their experiences and findings by writing a short report which addressed four questions: What did you investigate? How did you do 
it? What did you find? What are your conclusions? Modeled after the four sections generally found in scientific reports- introduction, methods, results and discussion. The reports were used to assess participants' scientific skills, and abilities to plan, execute and analyze personal research. They were analyzed based on use of scientific practices (such as asking research questions and defining problems) and compliance with scientific methodologies (such as control and replication), based on the National Research Council framework for K-12 science education [National Research Council (NRC), 2012].

Reports also included feedback on the project, indicating the positive and negative aspects of the project and recommendations for the future. While feedback on the project was implemented on a rolling basis to improve project management and design, this data was also thematically analyzed and used to determine participants' activities in the project, experiences and achievements from participation. This was used to reinforce the engagement styles and motivations identified throughout the study.

Online comments, and e-mail correspondence. Throughout the study, all comments sent through the project website, e-mail correspondence and conversations with participants, were documented in a field diary. Online comments and correspondence served to understand the participants' priorities and interests in the project. They were used as complementary information and to assist interpretation and perform triangulation of the data.

To understand how participants engaged with the online data presentation platform, the log data were accessed and mined to account for individual visitors. This provided information on the use patterns of the platform, in addition to the number of visits and the activities conducted by each visitor. Interactions were assessed both on an individual and group level, during a 30-month period (from the platform launch, until the completion of data collection). Over this time, 436 participants registered to the platform, which provided them access to the full set of information and data visualizations styles. Of these, 100 participants were recurrent and visited the site at least three times, and 45 participants visited 10 times or more.

Overall, registered participants engaged in 8885 activities within the platform. These included login, general interactions (e.g. loading the air quality map, toggling between tabs), choosing a sensor, viewing data, interacting with pollution chart (e.g. changing time frames, choosing air pollutants to be displayed), viewing information about the platform and air quality, and reporting hazards, as detailed in Table 1. Our data reveals, most of the interactions with the platform $(41.6 \%)$ were related to viewing and interacting with the air quality data provided in the platform (choosing sensors + viewing data + chart interactions). While platform users could also contribute data by reporting on air quality hazards they identified, this feature was not broadly used and accounts for only $0.5 \%$ of interactions.

In addition to registered participants, the platform was accesses by over 2000 visitors, who had access to the general map providing spatial air quality information. 
Table 1. Interactions with Sensing the Air platform by registered platform participants.

\begin{tabular}{|lllr|}
\hline Type of interaction & \% of total interaction \\
\hline \multirow{3}{*}{$\begin{array}{l}\text { View } \\
\text { information }\end{array}$} & About platform & 17.5 & 23.8 \\
\cline { 2 - 3 } & Detailed scientific information & 3.8 & \\
\cline { 2 - 3 } & Pollutant explanations & 1.5 & \\
\cline { 2 - 3 } & About stations & 1 & \\
\hline General interactions & & 17.5 \\
\hline Choosing sensors & & 17 \\
\hline Login & & 4.9 & 16.6 \\
\hline View data & Chart & 13.5 \\
\cline { 2 - 3 } & Pollutant Data & \\
\cline { 2 - 3 } & Images & 3.8 & \\
\cline { 2 - 3 } & Station Data & \\
\cline { 2 - 3 } & Hazard reports & \\
\hline Chart Interactions & & \\
\hline Report hazards & & \\
\hline
\end{tabular}

\section{Importance of data accessibility}

Further to the general use patterns of the platform, it was of interest to investigate participants on a more individual level and understand their motivations for accessing the platform and perceptions of it as a way to disseminate air quality information. Using an online questionnaire, platform participants were asked about the significance of the platform from their point of view, and why they choose to engage with it. The analysis of the answers revealed a number of themes indicative of the importance of data accessibility, especially in a sensitive topic such as air quality (see Figure 1). No differences were identified between participants as a function of gender, age group or level of education.

Overall, $41 \%$ of respondents specifically indicated the platform is of great importance. Over a quarter of respondents $(28 \%)$ described the significance of transparency and accessibility of data, as illustrated by the following statement: "the importance of the platform is to provide information on air quality to the general public". The data furnished residents with information about their local environment since "Each individual has the right to know the dangers and implications for health of the environment- both in the home and the workplace, especially in a polluted city like Haifa." Other respondents (21\%) underscored the importance in raising awareness about air quality issues, stating the need for "social awareness of air pollution problems by citizens, in their environment". The platform was shown to actively engage the public, and was described as: "The only project I know of that includes the public in research, and gives the feeling that the public is an integral part of air pollution problems in Haifa". A few respondents (14\%) felt that the platform could help people "plan their day, choose where to buy a house, make decisions, etc.", or more broadly help protect the environment and improve health outcomes (14\%), so we can "live in a cleaner place and maintain our health."

One respondent felt the platform was not useful, and explained: "This does not interest me, I am a person who buries my head in the sand, I don't even watch the news so much". Although there was only one instance of this type of response it is an important point to consider when discussing public use and application of scientific data, since in some cases non-participation is the result of a deliberate decision. 
Data transparency \& accesibility

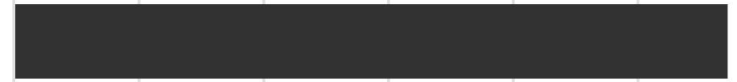

Raising awarness

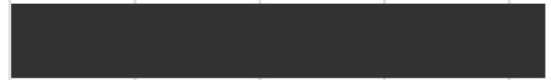

Decision making

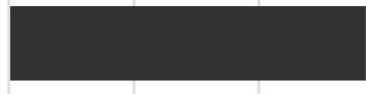

Health \& environmental protection

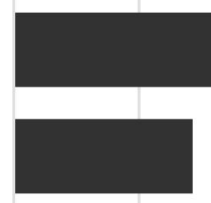

Public engagement

I don't know/not important

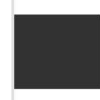

$\mathbf{0}$

5

$10 \quad 15 \quad 20$

25

30

Figure 1. Themes raised by platform participants, indicative of the importance of Sensing the Air platform.

\section{Sensor participants}

Further to the analysis of platform participants, it was of special interest to investigate those participants who actively engaged in air quality data collection. Sensor participation was a multi-dimensional practice, achieved by enabling participants to explore their own research questions while conducting experiments and air quality measurements in their local environment. In order to examine how this open-ended inquiry process inspired participants engagement styles, we followed the activities of twenty-five participants over-time. Using multiple research tools, we identified participant's motivations, main activities conducted in the project, previous knowledge, perceptions of air quality, and experiences with the project.

The investigations conducted by participants varied in time and space and spanned both indoor and outdoor measurements. Since participants were looking for information regarding their personal lives, investigations centered around their homes, offices and day-to-day routines. Many of the participants examined the air quality in their house, investigations which included a comparison of air quality between different rooms, between indoor and outdoor environments and examination of indoor air quality while cooking. Other participants measured outdoor air quality over time, hanging the sensor outside the window or placing it on a terrace or garden. One participant examined air quality on her daily commute to work, and a teacher who participated, examined air quality at the entrance to the school during rush hour, and off-peak hours, investigating the differences. Interestingly, the majority of these investigations addressed personal and local issues, ones which people often encounter in their daily life. 
Through ongoing communication with Sensing the Air participants and analysis of their reports and interviews, a number of themes arise, demonstrating participants motivations, activities and experiences within the project. Together, these themes demonstrate a range of engagement styles, perceptions and levels of commitment by Sensing the Air participants. While some participants held one overarching engagement style, categorized by one of the following themes, others had a combination of several. This illustrate the complexity and interconnectivity between participants motivations, activities engaged within the project, satisfaction and achievements.

Worried residents. The "worried residents" was the most abundant theme arising from the analysis with eleven participants indicating this was a motivation for participation in Sensing the Air (sometimes in addition to other motivations). Many (but not all), of these participants live in the Haifa area, hear about air quality problems and pollution and are concerned and cautious. They are worried about the health implications of air pollution, especially on their children's health, and want to know whether by living in Haifa they are endangering their family. As one of the participants stated: "I feel this is my responsibility as a parent... I don't want to take the chance my children will become sick" (Par \#6). Participants indicated they do not have the information they need to make decisions and that their participation in Sensing the Air is an attempt to find some answers to these uncertainties. One participant explained this stance: "There is a lot of uncertainty. I don't really know what's going on in terms of air pollution" (Par \#2). Another participant exclaimed when asked about the level of air pollution in Haifa: "Interesting question. That is a secret." He continued: "We don't know what the truth is ... we have no real data" (Par \#1).

This feeling of uncertainty motivated the worried residents to engage with Sensing the Air and conduct air quality measurements and investigations. Many participants measured outdoor air quality in their immediate environment over time, in an attempt to understand air quality levels and if it is really as bad as often claimed in the media. Another type of investigation of outdoor air quality was exemplified by a worried resident comparing air quality measurement in three areas of the city. The participant explained that her family is looking to buy a house and: "when we think where we want to make our home, the air quality issue is important and relevant to us, a topic we want to take into account" (Par \#13). An additional example of an investigation conducted by a worried resident is the measurement of air particles outside an office. The participant explained his office is adjacent to two industrial facilities which produce noxious odors, and dust which accumulates on vehicles. He explained that while the dust is a great inconvenience, his real concern is its health implications: "My father had cancer. He didn't work in one of these industrial facilities, he had a private office, but to me, this is one of the thoughts that come to mind - pollution, industry, bad smells, all these things cause cancer" (Par \#20).

Participants engaging with Sensing the Air for these reasons, generally reported a positive experience with the project as it provided them with the opportunity to investigate air quality in their places of interest, enabling them to make informed decisions. As one of the participants indicated in the feedback form: "The measuring device gives me information that may help me reduce the amount of pollutants in the area." He later said: "I think every project that tries to save the environment and addresses 
people and their quality of life, is important. I am extremely pleased [with my participation]" (Par \#20).

Education and outreach. Six of the participants indicated their motivation to participate in the project was related to education and raising awareness to air quality topics. Of these, three participants were teachers who looked to involve their students in the project, considering it an interesting, relevant, and innovative way to engage and motivate students. They also believed that engaging their students in authentic research was exciting, could promote their learning processes and strengthen their understanding of scientific inquiry. One of the teachers explained her interest in participating as follows: "This topic concerns us in the Haifa area, with all the industries. It's something the students are aware of. It's authentic and relevant to them" (Par \#22).

Additional participants who were motivated by education and outreach were excited by the opportunities provided by Sensing the Air in terms of data accessibility and transparency. One participant explained the importance of the project in involving the public with science and saw it as one solution to the social problem he defined as: "the lack of transparency and lack of public participation in the decision-making process related to air pollution in Haifa, which results in public distrust" (Par \#9).

Participants who indicated the importance of the platform in these ways, were usually familiar with air pollution topics attained through media coverage and conversations with families and friends. They expressed their personal learning through participation and indicated they feel empowered by their participation, for example: "I feel [the sensor] gives me a lot of power to control my exposure" (Par \#23). Participants viewed the project as an important public engagement initiative, had a positive experience and volunteered to help spread the word and attract more participants to the project, indicated by one of the participants: "This is very important project. I take it upon myself to recruit others [...] to support scientific research and develop research skills in the service of society" (Par \#17).

Environmental action. A number of participants $(\mathrm{N}=4)$ indicated they were motivated to participate in Sensing the Air due to civic and environmental action. These participants were generally already engaged in environmental activities and perceived their involvement in the project as an additional activist activity. In the words of one of the participants: "We are a growing group of activists contesting [industry development] programs the government wants to introduce [in Haifa bay]" (Par \#11). The participants motivated by civic action were interested in the air quality data received form the air sensors, but were not necessarily interested in the scientific applications of the data. Their motivation for participating was to gain information, experience, and familiarity with air pollution issues, facilitating their civic action rather than promoting scientific research. This was echoed in the words of the participants who asked, regarding the information obtained from the sensors: "Does this have any significance beyond research activity? Political influence is what really matters" (Par \#12).

This theme differs from the worried resident theme since it incorporates participants who have been proactive about air quality for some time and are 
interested in improving air quality in their city for the benefit of the community at large. Many of these participants understood air quality concepts and were able to discuss municipal monitoring systems in great detail. For example, one of the participants who criticized the current governmental monitoring scheme explained: "Heavy metals have not been monitored since 2012 or 2013, although they are supposed to be measured twice a year" (Par \#8). They are often opinionated about air quality in their location, do not trust the authorities, and do not trust the official air monitoring systems used by the government. They engaged in Sensing the Air as an external body that can provide reliable, unbiased data. As indicated by one of the participants: "There is a need for someone we can trust. Some independent body that is not funded by them [ industry]" (Par \#12).

In many ways these participants wanted the data collected to support their predefined opinion about air quality. They perceived the air quality in the area as bad and were looking for the data to support this opinion. When the data did not support their opinion, some participants claimed the project did not meet their needs or was not sufficient to produce the data that they were looking for. They hence ended their participation in the project and either did not complete the personal investigations or did not submit the investigation reports. This was explained as a priority choice - as time was at a premium, they preferred spending it on activism rather than on long term research endeavors. An example of this emerges clearly from a message sent by one of the participants:

"Unfortunately I must inform you that I want to terminate my participation. I am already engaged in real activity with [an environmental activist]. I do not have time to do things for research" (Par \#11).

Personal interest. Rather than emphasizing on external motivations, some participants $(\mathrm{N}=4)$ indicated they were genuinely interested in the topic of air quality. These participants had many questions about air quality and many ideas on ways to conduct personalized research on the topic. Their motivation to participate was to acquire the air-sensing monitors, which would provide the infrastructure and data to support these investigations. They enjoyed the process of planning and conducting experiments, invested considerable time and tried to be as accurate as possible. For example, one of the participants while planning his experiment, asked: "Are there any calibration measurements you have conducted under controlled conditions, to check sensor readings relative to objective concentrations?" (Par \#19). The experiments conducted by these participants often had many variables and were designed to compare air quality in various locations over time (while maintaining good scientific practices, as indicated above). One of the participants expressed her disappointment that she could only borrow one air sensor: "What I really want to do, is examine air quality at home, and compare it to different locations. If I had twenty sensors, I would be able to do this" (Par \#18). Some participants performed a number of experiments and thus provided a few scientific reports (one participant provided five separate reports).

Participants motived by their personal interest, understood scientific concepts and exhibited many scientific competences which were reflected in their written reports. They made use of concepts such as control, replication and uncertainty, understood the limitations of the study and tried to explore all variables and indicate their reservations about the reliability and validity of the results (similar to reservations often found in scientific reports written by scientists). An example of 
the use of scientific skills is illustrated in the following transcript from one of the reports: "I placed the sensor a couple of $\mathrm{cm}$ from the stove. I measured background levels of NO2, then turned on the flame. [comparison] The experiment was performed at two separate times. [replication] The experiment is qualitative in the sense and there is no quantitative measurement of "how much gas was consumed" [limitations] ." When presenting the results, he explained that some data outliers were "probably due to pre-ignition of the gas prior to placing the sensor [...] which may affect the accuracy of the experiment" [reliability and validity] (Par \#19). It should be noted that three out of the four participants who indicated their personal interest in air quality, had previous scientific training and were scientists by profession. However, this was not always the case since other participants with a similar professional background did not express such an interest.

Participants generally had a positive experience from Sensing the Air, but indicated its inability to provide more sophisticated equipment and research flexibility, as indicated by one of the participant's feedback: "I would like to measure [additional pollutants] as well for a more complete picture of my air quality. But in general, really enjoyed being empowered by the knowledge I obtained [...] it has inspired me to do further research" (case study \#23).

Opportunistic. A number of participants $(\mathrm{N}=4)$ stumbled across the project in a specific time of need, as they had been exposed to an air quality hazard and were looking for answers about their air pollution exposure. A few of these participants approached Sensing the Air after a large residential fire in Haifa (in Nov. 2017) which destroyed many houses and damaged others. The participants, whose houses were damaged, sought reassurance about the concentration of pollutants in their homes after the fire. Their interest in the project, and hence their investigations were highly circumscribed to answering these specific questions. Similarly, a participant who joined the Lag B'Omer (a Jewish holiday associated with the custom of lighting bonfires) monitoring project was focused on monitoring air quality at the bonfire area as a one-time activity.

Such participation was opportunistic by nature, participants did not become more active in the project and did not participate in additional project activities. Their contribution was very practical and focused. Yet, they were excited about the opportunities the project provided and viewed it as important and empowering. For example, one of the participants wrote after monitoring air quality in her home: "I think this platform is incredibly important, and I am so glad to have learned about it" (case study \#15). Nevertheless, she did not continue to engage with the project or platform on other issues.

Discussion

This paper aimed to identify the diverse ways in which participants interact and engage with Sensing the Air project and characterize the reasons driving their engagement. This was done by examining two distinct, yet equally important participant groups, which engaged either as platform or as sensor participants. While both groups of participants actively engaged with air quality science, our findings illustrate the unique characteristics of different participants, highlighting the diverse motivations and activities conducted within the project. 
Platform participants were found to mostly engage by viewing and interacting with the various air quality data provided in the platform and reading information about the platform. They interacted to a lesser degree with reading general air quality information and explanations, and reporting hazards. Participants views on the importance of the platform echo these interactions as they indicate it provides important real-time information and raises their awareness. While this finding provides important insight on the overall use of the platform, it fails to realize the diversity of participants, categorizing all platform participants in one group, (as often done in the literature discussing stakeholders of citizen science). To mitigate this challenge and account for the diversity of activities conducted by participants within the project and the drivers supporting their participation, sensor participants were investigated on an individual level. Through an in-depth investigation into sensor participants experiences, five themes were identified which are indicative of participants motivations and engagement styles within Sensing the air: worried residents, education and outreach, environmental action, personal interest and opportunistic engagement.

The work presented here clearly points to the diverse nature of participants, their varying level of engagement and the different motivations driving participation, all within one project. It demonstrates how personal goals and motivations can play an important role in directing engagement styles within citizen science. While participants had a complex set of motivations for engaging in Sensing the Air, some participants had an overarching motivation which can be linked to the activities they engaged with in the project, their satisfaction and achievements. An example for this is participation motivated by participant's environmental activities, which as our finding suggest, were often discouraged when participation required more time than expected, did not meet their activist's goals, or affected their other volunteer activities. A perhaps more positive example is that of participants motivated by education and outreach, and in particular teachers, who engaged on the basis of involving their schools and students in the project. Through Sensing the Air, teachers involved their students in authentic research, conducted measurements of air quality, compared and analyzed results and formulated conclusions. The teachers were very happy with their experiences which satisfied their initial goals and volunteered to help recruit additional teachers and schools for the project.

Many studies have investigated motivations for participating in citizen science initiatives [e.g. Land-Zandstra et al., 2016; Nov, Arazy and Anderson, 2011; Raddick et al., 2013]. These have suggested that participation is driven by both intrinsic (activity performed out of interest, enjoyment and/or satisfaction) and extrinsic (activity performed out of social pressure, avoiding guilt, and/or environmental concerns) motivations, depending on the participant and the project. According to Ryan and Deci [2000], the founding fathers of self-determination theory (SDT), there is a continuum between extrinsic and intrinsic motivation, where decisions are made autonomously but in order to achieve an external goal. This continuum is well reflected in this study which identified externally motivated participants for environmental action reasons alongside worried residents, who were externally motivated for intrinsic reasons, and intrinsically motivated participants with personal interests of air quality. This study also outlines the various motivations of platform participants, from increasing data transparency and accessibility, through health and environmental 
protection and informed decision making, all motivated by key values which are captured within the extrinsic-intrinsic continuum.

Motivations for participating in citizen science can also vary across projects and topics. Sensing the Air has a strong environmental emphasis and addresses a controversial pollution related topic. With a topic so relevant to people's lives, the main motivation for participating, across all engagement styles, was addressing personal needs rather than an altruistic motivation such as the advancement of science. Similarly, Phillips et al. [2019] found that in two environmental hazard - related citizen science projects (monitoring air and water quality), participants were greatly influenced by worry and concern. This contrasts with projects monitoring natural phenomena in which motivations were found to be mainly connected to interest, contribution, and enjoyment [Phillips et al., 2019]. Since different citizen science projects attract participants with diverse motivations, they may display different engagement styles than the ones identified and presented in this study. For example, an ecological monitoring project may attract participants with other engagement styles, such as "nature lovers" or "family oriented" participants. Similarly, some of the styles found here, such as worried residents, may not be found in projects with different fields and scopes.

Inclusiveness in citizen science. While inclusiveness was a goal of this project, it is not clear that this was satisfactorily met, with a large percentage of highly educated participants involved as both platform and sensor participants. Furthermore, a close look at the project population overtime reveals that as the project developed offering more complex tasks, the diversity of participants has declined. This is an inherent concern in many citizen science projects which tends to appeal to a narrow type of audience, namely, those already attentive to and supportive of science [Martin, 2017].

In our previous research [Golumbic, Fishbain and Baram-Tsabari, 2019] we reported on the importance of a flexible, interactive platform for data presentation which provides various opportunities and levels of information to support diverse participation patterns. As argued, we believe this is key for creating an inclusive and inviting environment for all citizens to take part in. While clearly, there is room for improvement, our sample does reveal diversity in participants' ages and gender indicating the project appeals to a wider audience than previously reported in the citizen science literature [Soleri et al., 2016].

As such, we conclude that the lack of full diversity may be mitigated by flexible project design and implementation of a diversity of tasks and activities that support multiple participants' goals, abilities and interests. In order to attract a greater range of participants in citizen science, a clearer understanding of different target audiences and how best to recruit and retain their participation is crucial. Creating a flexible and personalized environment for participants with different goals could introduce personal value for participants and expand citizen science to new audiences that are not necessarily intrinsically motivated to engage with science. Implementing such a practice in citizen science could promote the social impact of citizen science and further increase public engagement with science. 
Towards an interrelated citizen science - science communication practice.

Citizen science projects encompass many science communication practices which include engaging non-scientists in science, explaining scientific terms and disseminating scientific findings [Constant and Roberts, 2017; Golumbic, Baram-Tsabari and Koichu, 2019]. This notion is exemplified in this study which combines citizen science practices (air quality monitoring) with science communication practices (facilitating the dissemination of air quality information). While each field has its individual history, theories and models, many similarities exit which provide opportunities to integrate practices and advance research in both fields.

Sensing the Air utilizes a unique combination of science communication models, consolidating them to create a hybrid "citizen science: science communication" practice. A good example for this combined practice is illustrated in the data presentation platform, seemingly a one-way transfer of scientific information, which may align with the deficit model. However, this platform was designed with a user-centered approach that created dialogue and guaranteed the presentation of relevant information - a key feature of the dialogue model. This platform, as indicated by project participants, had great importance in terms of data accessibility, transparency and raising public awareness. While viewing web data may not be considered a citizen science related activity by some, we argue it is an important aspect of citizen science which demonstrates the value of citizen generated data not only for scientists, but for many members of the community.

Brossard and Lewenstein [2009] discuss a combination of science communication models, with the deficit model serving as a backbone for applying additional models (contextual, lay expertise and dialogue models). They provide examples of science communication projects in which understanding of scientific concepts was considered a prerequisite to any type of discussion. Similarly, Mejlgaard and Stares [2010] suggest that scientific knowledge development is an essential first step for democratic participation in scientific processes and decision-making.

Here, a new approach is considered where various science communication models, facilitated by citizen science practice, are used jointly to build a platform which meets the needs of the community, is based on their requirements and has a vision of transparency and inclusion. Such a practice and combination of models brings the best from each theoretical tradition, advancing the theory and practice of the field [Haywood and Besley, 2014] and demonstrating the interconnectivity of science communication and citizen science.

Engaging the public with science can take many forms, from attending a scientific talk, through reading popular science articles and being active on scientific social media platforms. Many of these practices are well integrated in citizen science, which provides a spectrum of engagement opportunities with science. Yet, citizen science extends these activities to engage the public in more participatory, innovative and exciting ways. It offers flexible and dynamic engagement opportunities, tailored towards diverse audiences, levels of engagement and personal goals, all potentially within one project. Such a practice offers the opportunity to revisit science communication models, while considering an adoptive approach for their implementation. Recognizing and establishing the relationship between science communication and citizen science models and practices 
is an important milestone for the advancement of science communication alongside citizen science, and could bring to fruitful exploration, integration and growth.

\section{References}

Aristeidou, M., Scanlon, E. and Sharples, M. (2017). 'Profiles of engagement in online communities of citizen science participation'. Computers in Human Behavior 74, pp. 246-256. https: //doi.org/10.1016/j.chb.2017.04.044.

Bauer, M. W. (2009). 'The Evolution of Public Understanding of Science Discourse and Comparative Evidence'. Science, Technology and Society 14 (2), p. 221. https://doi.org/10.1177/097172180901400202.

Bazeley, P. (2013). Qualitative data analysis: practical strategies. Sage.

Bonney, R., Ballard, H., Jordan, R., McCallie, E., Phillips, T., Shirk, J. and Wilderman, C. C. (2009). Public Participation in Scientific Research: Defining the Field and Assessing Its Potential for Informal Science Education. A CAISE Inquiry Group Report. Washington, D.C., U.S.A.: Center for Advancement of Informal Science Education (CAISE). URL: http://www. informalscience.org/public-p articipation-scientific-research-defining-field-and-assessing-its-p otential-informal-science.

Bonney, R., Phillips, T. B., Ballard, H. L. and Enck, J. W. (2016). 'Can citizen science enhance public understanding of science?' Public Understanding of Science 25 (1), pp. 2-16. https://doi.org/10.1177/0963662515607406.

Bonney, R., Shirk, J. L., Phillips, T. B., Wiggins, A., Ballard, H. L., Miller-Rushing, A. J. and Parrish, J. K. (2014). 'Citizen science. Next steps for citizen science'. Science 343 (6178), pp. 1436-1437. https://doi.org/10.1126/science.1251554. PMID: 24675940.

Brossard, D. and Lewenstein, B. (2009). 'A critical appraisal of models of public understanding of science: using practice to inform theory'. In: Communicating science. New agendas in communication. Ed. by L. Kahlor and P. Stout. New York, NY, U.S.A.: Routledge, pp. 11-39. https://doi.org/10.4324/9780203867631.

Bucchi, M. and Trench, B., eds. (2014). Routledge Handbook of Public Communication of Science and Technology. 2nd ed. London, U.K. and New York, U.S.A.: Routledge. https://doi .org/10.4324/9780203483794.

Chako, S. and Levontin, L. (2019). Motivation for citizen science scale - the development process. Technical report.

Constant, N. and Roberts, L. (2017). 'Narratives as a mode of research evaluation in citizen science: understanding broader science communication impacts'. JCOM 16 (04), A03. https://doi.org/10.22323/2.16040203.

Cox, J., Oh, E. Y., Simmons, B., Graham, G., Greenhill, A., Lintott, C., Masters, K. and Woodcock, J. (2018). 'Doing good online: the changing relationships between motivations, activity and retention among online volunteers'. Nonprofit and Voluntary Sector Quarterly 47 (5), pp. 1031-1056. https://doi.org/10.1177/0899764018783066.

Domroese, M. C. and Johnson, E. A. (2017). 'Why watch bees? Motivations of citizen science volunteers in the Great Pollinator Project'. Biological Conservation 208, pp. 40-47. https: //doi.org/10.1016/j.biocon.2016.08.020.

Eveleigh, A. M. M., Jennett, C., Blandford, A., Brohan, P. and Cox, A. L. (2014). 'Designing for dabblers and deterring drop-outs in citizen science'. In: Proceedings of the IGCHI Conference on Human Factors in Computing Systems (CHI '14). New York, NY, U.S.A.: ACM Press, pp. 2985-2994. https://doi.org/10.1145/2556288.2557262. 
Golumbic, Y. N., Baram-Tsabari, A. and Koichu, B. (2019). 'Engagement and communication features of scientifically successful citizen science projects'. Environmental Communication 14 (4), pp. 465-480. https://doi.org/10.1080/17524032.2019.1687101.

Golumbic, Y. N., Fishbain, B. and Baram-Tsabari, A. (2019). ‘User centered design of a citizen science air-quality monitoring project'. International Journal of Science Education, Part B 9 (3), pp. 195-213. https://doi.org/10.1080/21548455.2019.1597314.

- (2020). 'Science literacy in action: understanding scientific data presented in a citizen science platform by non-expert adults'. International Journal of Science Education, Part B, pp. 1-16. https://doi.org/10.1080/21548455.2020.1769877.

Golumbic, Y. N., Orr, D., Baram-Tsabari, A. and Fishbain, B. (2017). 'Between vision and reality: a case study of scientists' views on citizen science'. Citizen Science: Theory and Practice 2 (1), p. 6. https://doi .org/10.5334/cstp. 53.

Grace, L. K. J., Maheswari, V. and Nagamalai, D. (2011). 'Web log data analysis and mining'. In: Communications in computer and information science. Ed. by N. Meghanathan, B. K. Kaushik and D. Nagamalai. Vol. 133. Berlin, Heidelberg, Germany: Springer, pp. 459-469. https://doi.org/10.1007/978-3-642-17881-8_44.

Guest, G., MacQueen, K. and Namey, E. (2012). Applied thematic analysis. SAGE Publications, Inc. https://doi .org/10.4135/9781483384436.

Haklay, M. (2013). 'Citizen Science and Volunteered Geographic Information: Overview and Typology of Participation'. In: Crowdsourcing Geographic Knowledge: Volunteered Geographic Information (VGI) in Theory and Practice. Ed. by D. Sui, S. Elwood and M. Goodchild. Berlin, Germany: Springer, pp. 105-122. https://doi.org/10.1007/978-94-007-4587-2_7.

Haywood, B. K. and Besley, J. C. (2014). 'Education, outreach, and inclusive engagement: Towards integrated indicators of successful program outcomes in participatory science'. Public Understanding of Science 23 (1), pp. 92-106. https://doi.org/10.1177/0963662513494560.

Israel Ministry of Environmental Protection (2015). Air pollution in Haifa Bay. URL: $\mathrm{h}$ ttp://www.sviva.gov.il/English/env_topics/IndustryAndBusinessLicensi ng/Haifa-Bay-Industrial-Zone/Pages/Air-Pollution-in-Haifa-Bay . aspx.

Jackson, C., Østerlund, C., Maidel, V., Crowston, K. and Mugar, G. (2016). 'Which way did they go? Newcomer movement through the Zooniverse'. In: Proceedings of the $19^{\text {th }}$ ACM Conference on Computer-Supported Cooperative Work $\mathcal{E}$ Social Computing - CSCW'16. ACM Press, pp. 623-634. https://doi.org/10.1145/2818048.2835197.

Land-Zandstra, A. M., Devilee, J. L. A., Snik, F., Buurmeijer, F. and van den Broek, J. M. (2016). 'Citizen science on a smartphone: Participants' motivations and learning'. Public Understanding of Science 25 (1), pp. 45-60. https://doi.org/10.1177/0963662515602406.

Martin, V. Y. (2017). 'Citizen science as a means for increasing public engagement in science'. Science Communication 39 (2), pp. 142-168. https://doi.org/10.1177/1075547017696165.

McCallie, E., Bell, L., Lohwater, T., Falk, J. H., Lehr, J. L., Lewenstein, B. V. and Needham, C. (2009). Many Experts, Many Audiences: Public Engagement with Science and Informal Science Education. Washington, D.C., U.S.A.: Center for Advancement of Informal Science Education (CAISE).

URL: http://digitalcommons.calpoly.edu/eth_fac/12/. 
Mejlgaard, N. and Stares, S. (2010). 'Participation and competence as joint components in a cross-national analysis of scientific citizenship'. Public Understanding of Science 19 (5), pp. 545-561. https://doi.org/10.1177/0963662509335456.

National Research Council (NRC) (2012). A framework for K-12 science education: practices, crosscutting concepts and core ideas. Washington, DC, U.S.A.: National Academy Press. https : //doi .org/10.17226/13165.

Nov, O., Arazy, O. and Anderson, D. (2011). 'Technology-mediated citizen science participation: a motivational model'. In: Proceedings of the Fifth international AAAI Conference on Weblogs and Social Media (Barcelona, Spain), pp. 249-256.

Patton, M. Q. (1999). 'Enhancing the quality and credibility of qualitative analysis'. Health Services Research 34 (5 Pt 2), pp. 1189-1208. PMID: 10591279.

Phillips, T. B., Ballard, H. L., Lewenstein, B. V. and Bonney, R. (2019). 'Engagement in science through citizen science: moving beyond data collection'. Science Education 103 (3), pp. 665-690. https://doi.org/10.1002/sce.21501.

Raddick, M. J., Bracey, G., Gay, P. L., Lintott, C. J., Cardamone, C., Murray, P., Schawinski, K., Szalay, A. S. and Vandenberg, J. (2013). ‘Galaxy Zoo: Motivations of Citizen Scientists'. Astronomy Education Review 12 (1), pp. 010106-010101. https://doi.org/10.3847/AER2011021. arXiv: 1303.6886.

Rotman, D., Preece, J., Hammock, J., Procita, K., Hansen, D., Parr, C., Lewis, D. and Jacobs, D. (2012). 'Dynamic changes in motivation in collaborative citizen-science projects'. In: Proceedings of the ACM 2012 Conference on Computer Supported Cooperative Work (CSCW 2012) (Seattle, WA, U.S.A. 11th-15th February 2012). ACM Press, pp. 217-226. https://doi.org/10.1145/2145204.2145238.

Roy, H. E., Pocock, M. J. O., Preston, C. D., Roy, D. B., Savage, J., Tweddle, J. C. and Robinson, L. D. (2012). Understanding citizen science and environmental monitoring: final report on behalf of UK Environmental Observation Framework. URL: https: //ww w.ceh.ac.uk/sites/default/files/citizensciencereview.pdf.

Ryan, R. M. and Deci, E. L. (2000). 'Self-determination theory and the facilitation of intrinsic motivation, social development, and well-being'. The American Psychologist 55 (1), pp. 68-78. https://doi.org/10.1037/0003-066X.55.1.68. PMID: 11392867.

Sagy, O., Golumbic, Y. N., Abramsky, H. B.-H., Benichou, M., Atias, O., Manor Braham, H., Baram-Tsabari, A., Kali, Y., Ben-Zvi, D., Hod, Y. and Angel, D. (2019). 'Citizen science: an opportunity for learning in the networked society'. In: Learning in a networked society (LINKS). Cham, Switzerland: Springer International Publishing, pp. 97-115. https://doi.org/10.1007/978-3-030-14610-8_6.

Schrögel, P. and Kolleck, A. (2019). 'The many faces of participation in science: literature review and proposal for a three-dimensional framework'. Science $\mathcal{E}$ Technology Studies 32 (2), pp.77-99. https://doi.org/10.23987/sts . 59519.

Soleri, D., Long, J. W., Ramirez-Andreotta, M. D., Eitemiller, R. and Pandya, R. (2016). 'Finding pathways to more equitable and meaningful public-scientist partnerships'. Citizen Science: Theory and Practice 1 (1), p. 9. https://doi.org/10.5334/cstp. 46.

Storksdieck, M., Shirk, J. L., Cappadonna, J. L., Domroese, M., Göbel, C., Haklay, M., Miller-Rushing, A. J., Roetman, P., Sbrocchi, C. and Vohland, K. (2016). 'Associations for Citizen Science: Regional Knowledge, Global Collaboration'. Citizen Science: Theory and Practice 1 (2), pp. 1-10. https://doi.org/10.5334/cstp. 55. 
Thomas, D. R. (2006). 'A general inductive approach for analyzing qualitative evaluation data'. American Journal of Evaluation 27 (2), pp. 237-246. https://doi.org/10.1177/1098214005283748.

Tiago, P., Gouveia, M. J., Capinha, C., Santos-Reis, M. and Pereira, H. M. (2017). 'The influence of motivational factors on the frequency of participation in citizen science activities'. Nature Conservation 18, pp. 61-78. https://doi.org/10.3897/natureconservation.18.13429.

Trench, B. (2008). 'Towards an analytical framework of science communication models'. In: Communicating science in social contexts. Dordrecht, The Netherlands: Springer, pp. 119-135. https://doi.org/10.1007/978-1-4020-8598-7_7.

Wiggins, A. and Crowston, K. (2011). 'From Conservation to Crowdsourcing: a Typology of Citizen Science'. In: Proceedings of the $44^{\text {th }}$ Hawaii International Conference on System Sciences (HICSS-44). Kauai, HI, U.S.A. Pp. 1-10. https://doi.org/10.1109/HICSS . 2011.207.

- (2015). 'Surveying the citizen science landscape'. First Monday 20 (1-5). https://doi.org/10.5210/fm.v20i1.5520.

Yaela Golumbic is a science communication researcher, emphasizing on citizen science as a way for enhancing public participation and engagement with science. She is a postdoctoral fellow at the University of Sydney, and has developed, designed and managed several citizen science projects during the past five years, focusing on co-creation processes and wide community engagement. E-mail: yaelago123@gmail.com.

Ayelet Baram-Tsabari is an Associate Professor at the Faculty of Education in Science and Technology at the Technion - Israel Institute of Technology. Baram-Tsabari is a PI in the "Taking Citizen Science to School" research center, an elected member of the Israel Young Academy and the scientific committee of PCST and the founder of the Israeli Science Communication Conference series. Her research focuses on bridging science education and science communication scholarship to enable publics to use evidence effectively in decision making. E-mail: ayelet@technion.ac.il.

Barak Fishbain is an assistant Professor at the Environmental, Water and Agricultural Engineering Division, Faculty of Civil \& Environmental Engineering in the Technion-Israel Institute of Technology. Professor Fishbain served as an associate director at the Integrated Media Systems Center (IMSC), University of Southern California (USC) and did his post-doctoral studies at the department of Industrial Engineering and Operations Research (IEOR), University of California at Berkeley. His research focuses on Enviromatics, a research field aims at devising mathematical methods for machine understanding built and natural environments trends and behaviors. E-mail: fishbain@technion.ac.il.

How to cite

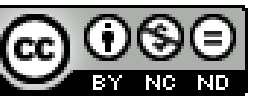

Golumbic, Y. N., Baram-Tsabari, A. and Fishbain, B. (2020). 'Engagement styles in an environmental citizen science project'. JCOM 19 (06), A03. https://doi.org/10.22323/2.19060203. 